\title{
Relay-race deformation mechanism during uniaxial tension of cylindrical samples of carbon steel: using digital image correlation technique
}

\author{
T.V. Tretiakova, V.E. Vildeman \\ Center of Experimental Mechanics, Perm National Research Polytechnic University, 614990, Komsomolsky av., 29, Perm, \\ Russia
}

\begin{abstract}
The work deals with experimental study of macro localization of plastic yielding occurrences of structural carbon steel, research of singularity of deformation wave processes by complex use of contemporary test equipment and high effective digital image correlation method. Evolution of nonuniform axial strain fields on surface of cylindrical samples during uniaxial tension was registered, time dependences were drawn, and a 'relay-race' mechanism of material deformation was found out at the stage of yield plateau forming. Strain concentration ratio was estimated for several material deformation stages.
\end{abstract}

KEYWORDS. Digital image correlation; Wave effects; Strain localization; Carbon steel.

\section{INTRODUCTION}

A great number of scientific literature deals with experimental study issues of plastic strain in solid bodies, specifically, authors repeatedly point out that plastic strain develops nonuniformly both in space (strain localization) and in time (time evolution of localization) [1,2]. Striking examples of plastic strain localization on macroscopic level are Chernov-Lüders Lines, initiation and evolution of necking effect on postcritical deformation stage $[3,4]$, and also waves of localized plastic strain.

The aim of this research was experimental investigation of regularities of plastic yielding macro localization for structural steel, study of singularities of wave deformation processes by complex use of contemporary testing equipment and noncontact strain measuring facilities.

\section{MATERIAL AND TEST PROCEDURE}

$\mathrm{S}$ tructural carbon steel 20 (GOST 1050-88) was chosen as the research subject. Mechanical tests on uniaxial tension of solid cylindrical samples (test portion length of $16 \mathrm{~mm}$, sample's diameter of $9.5 \mathrm{~mm}$ ) were conducted on Instron 8850 universal biaxial servo-hydraulic testing system with constant kinematic loading speed of $2 \% / \mathrm{min}$. Noncontact registration and displacement and strain fields review were carried out by three-dimensional Vic-3D digital optical system (Fig. 1). Video-system's software is based on digital image correlation technique (DIC). DIC is a highly effective non-contact, computer-vision-based method for measuring displacement and strain fields on specimen's surface by correlating digital images captured during loading or exploitation process [5].

The digital optical system can be used for problem solving of deformable solid mechanics: experimental investigation of nonuniform strain fields and analysis of failure conditions in bodies with concentrators of different geometry $[6,7]$, research of inelastic material deformation processes in complex strain-stress conditions, study of displacement and strain fields evolution during crack initiation, damage accumulation and material failure [8-10], etc. The video-system contains 
digital monochrome cameras, sample illumination systems, calibration grids, synchronizing hardware for communication with the test system, and specialized software which allows programming of video recording (Vic-Snap) and mathematical treatment of test data (Vic-3D). In Tab. 1 these parameters are shown.

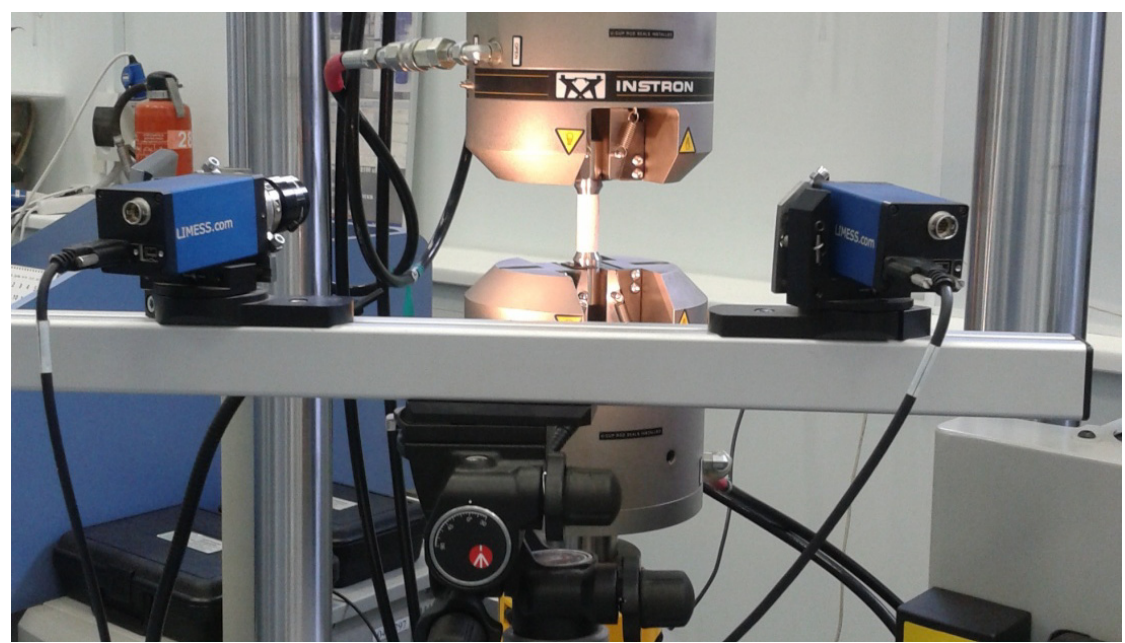

Figure 1: The non-contact three-dimensional digital optical system Vic-3D.

\begin{tabular}{cc}
\hline Hardware & 2 digital b/w DCP cameras \\
Resolution & $4 \mathrm{Mp}$ \\
Maximum videotaping speed & $15 \mathrm{image} / \mathrm{s}$ \\
Videotaping speed in current tests & $0.2 \mathrm{image} / \mathrm{s}$ \\
Software & 3D digital image correlation (Vic-3D) \\
Subset & 19 pixels \\
Step & 4 pixels \\
Correlation criteria & NSSD \\
Tensor type (strain calculation) & Lagrangian finite strain tensor \\
\hline
\end{tabular}

Table 1: Technical parameters of strain field registration.

Correlation of digital images was carried out by NSSD criteria (normalized sum of squared difference), which offers the best combination of flexibility and results.

$$
\chi_{N S S D}^{2}=\sum\left(\frac{\sum F_{i} G_{i}}{\sum G_{i}^{2}} G_{i}-F_{i}\right)^{2}
$$

In the software the Lagrangian finite strain tensor was used for strain field estimation:

$$
\varepsilon_{i j}=\frac{1}{2}\left(u_{i, j}+u_{j, i}+u_{k, i} u_{k, j}\right)
$$

\section{TEST RESULTS}

ests on uniaxial tension were carried out on 5 solid cylindrical samples. The tensile test diagram for carbon steel is shown in Fig. 2. The load-extension curve includes yield drop (II) and yield plateau (III-V) forming stages, and also an extensive post-critical deformation stage (VII-VIII).

Evolution of nonuniform axial strain fields for marked dots (I-VIII, Fig. 2), calculated by using the Vic-3D system, is illustrated in Fig. 3. At the elastoplastic deformation stage at the moment of transition through an upper yield point (point 
II), initiation and evolution of axial strain wave front (points III-V) was captured lengthwise the sample axis. Plastic strain is becoming macro localized during further loading at the material hardening stage (points VI, VII), which causes the necking effect in center part of the sample. At point VIII the deformed state of cylindrical samples equals its limit, at which macro scale destruction of material occurred.
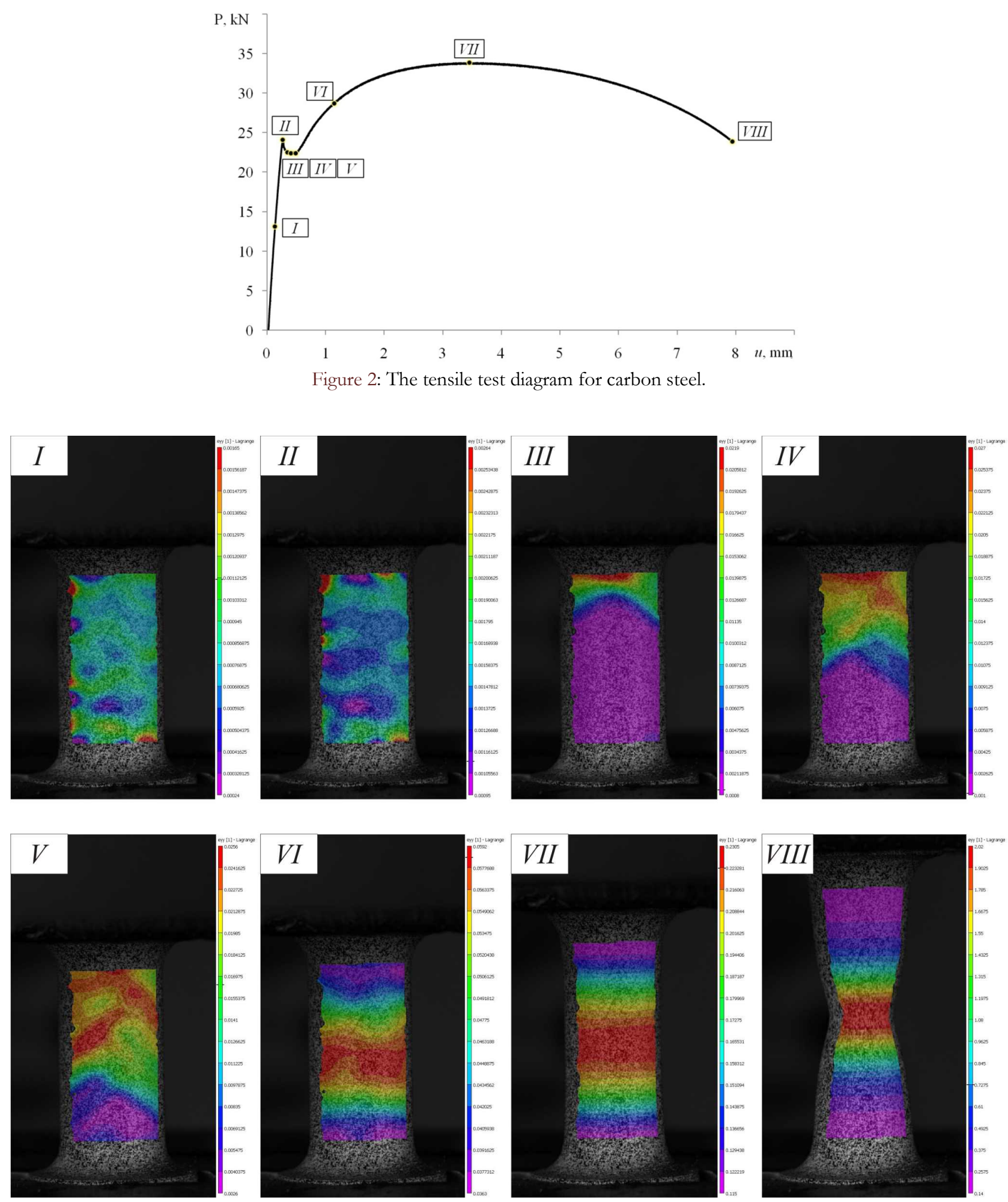

Figure 3: Evolution of axial strain fields during uniaxial tension of cylindrical sample. 
Axial strain distributions were drawn to appraise inhomogeneity of the material deformation process on sample surface (Fig. 4). Designation of curves (I-VIII) coincides with points on the tensile test diagram (Fig. 2). It is clear that at the moment before sample destruction, significant strain localization is observed in the central part and is about $\varepsilon_{y y}=200 \%$, while average strain is $32 \%$. The elasto-plastic material deformation stage demands for a more thorough study, specifically at the moment of yield drop and yield plateau forming (Fig. 5).
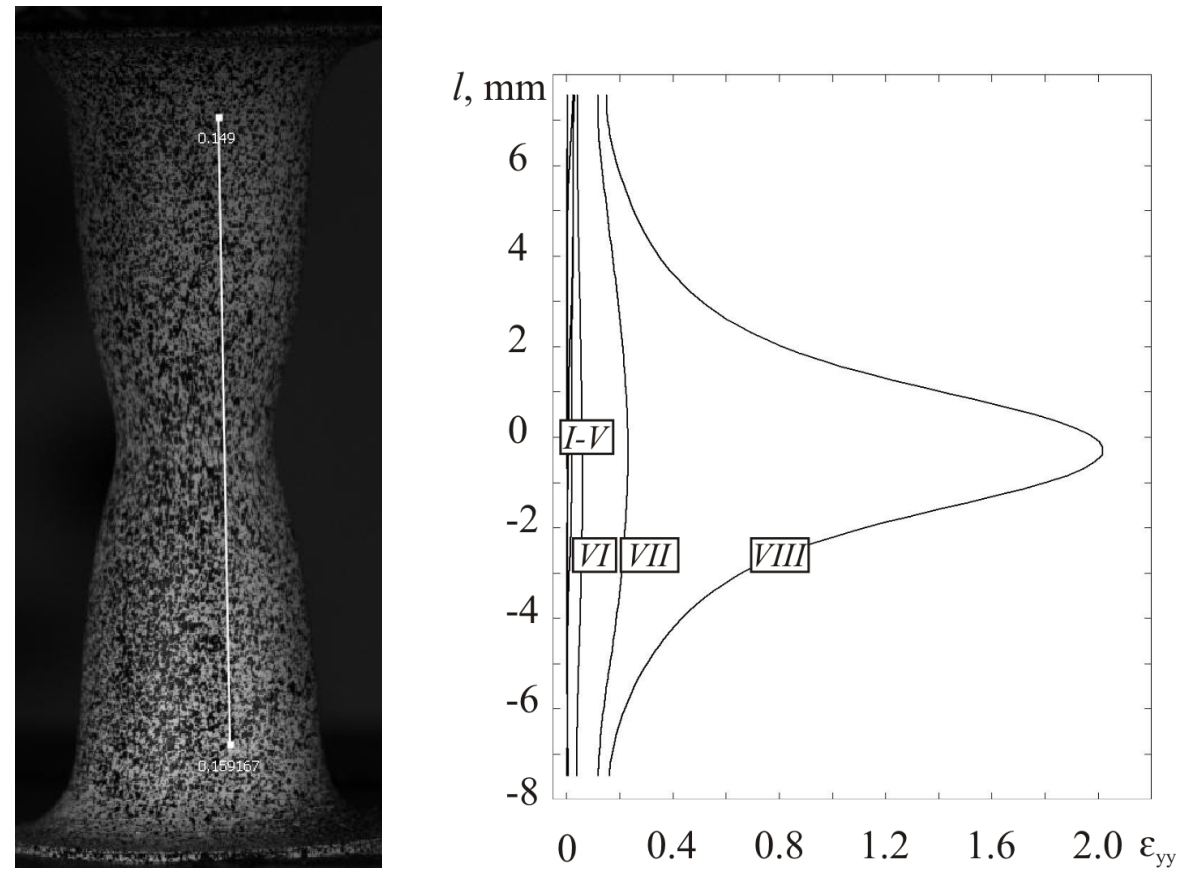

Figure 4: Axial strain distributions on surface of cylindrical sample.

At the elastic stage deformation of material was happening macro-homogeneously along the full sample length. As was mentioned above, the abrupt strain flash appeared (curve III, Fig. 5) at the moment of transition through an upper yield point (point II, Fig. 2), and a wave front of axial strain was initiated. The wave front is going from one grip to another with the speed of about $12-15 \mathrm{~mm} / \mathrm{min}$. Macro loading speed of the sample is $0.32 \mathrm{~mm} / \mathrm{min}$.

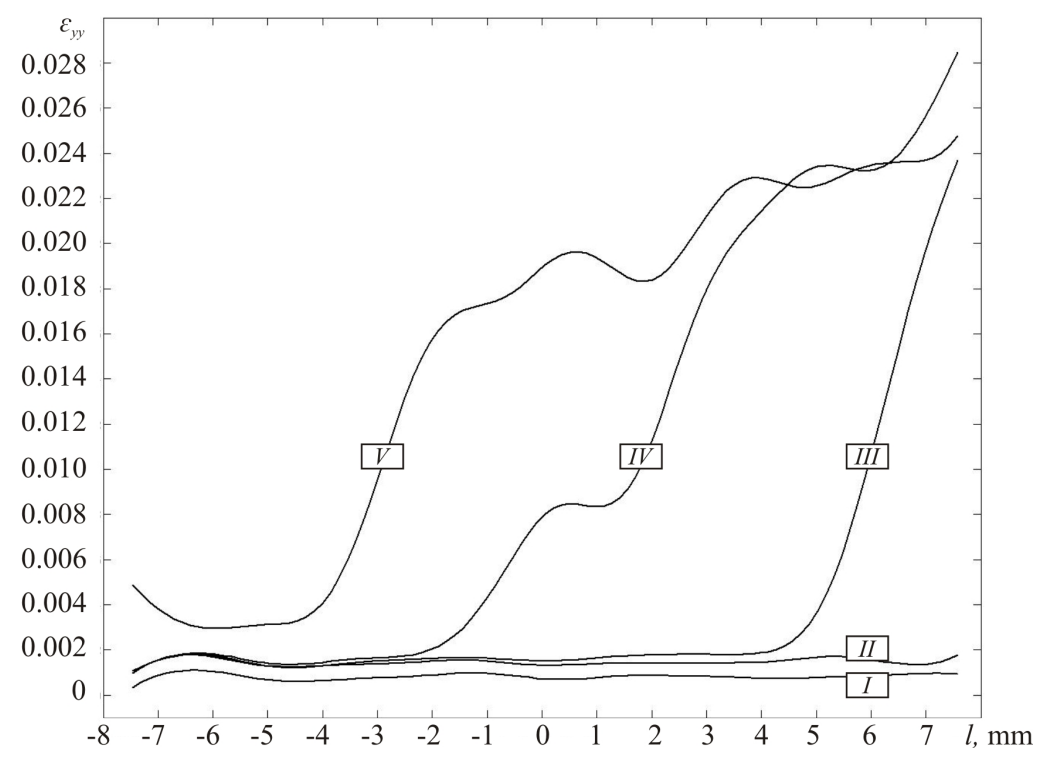

Figure 5: Axial strain distributions at the elasto-plastic deformation stage. 
On the basis of experimental data time dependences of axial strain were determined for five areas of material, marked on the surface of sample test portion (Fig. 6). At the material hardening stage and postcritical stage as well, the center point (1) speed of deformation is considerably higher than the other; at the same time, equidistance points (1 and 5, 2 and 4) deform with equal speed.

Time inhomogeneity on elasto-plastic stage has wave-like behavior (Fig. 7). The step-by-step involvement of parts of cylindrical samples into the material deformation process is observed (1-5, Fig. 7). Point 1, which is located at the edge of the sample test portion, starts first. When it reached a certain level of axial strain, the material stopped deforming in this area. During the deformation process, next point (2) is engaged, and so on. This effect can be named the 'relay-race mechanism' of deformation, which happens at the stage of yield plateau forming. During further loading at the material hardening stage the axial strain level increased at point 3. This fact confirms the occurrence of localization process in the center area of solid cylindrical sample test portion.

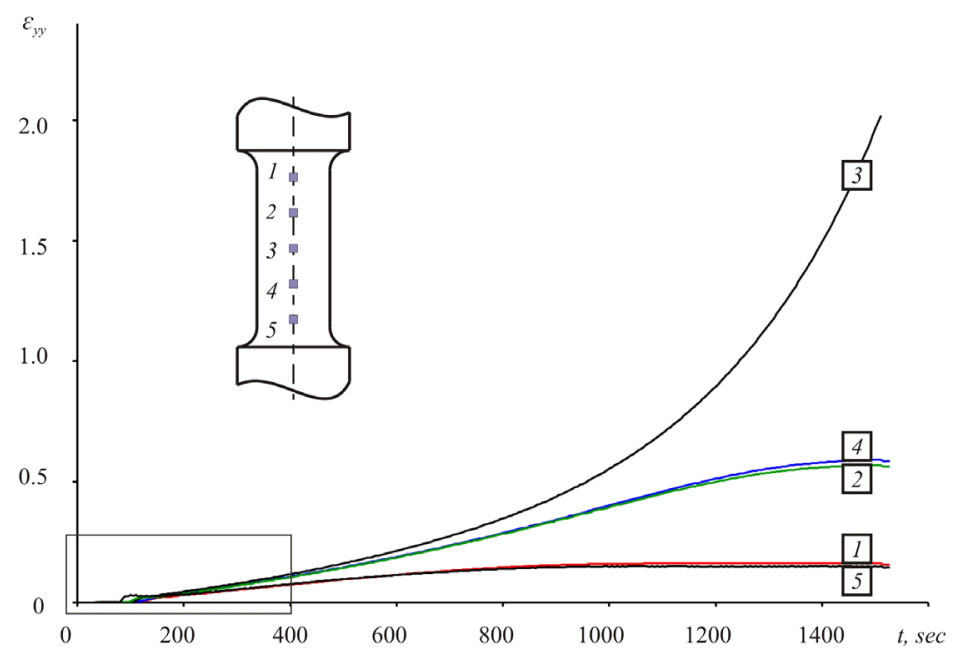

Figure 6: Time dependences of axial strain for five areas of material.

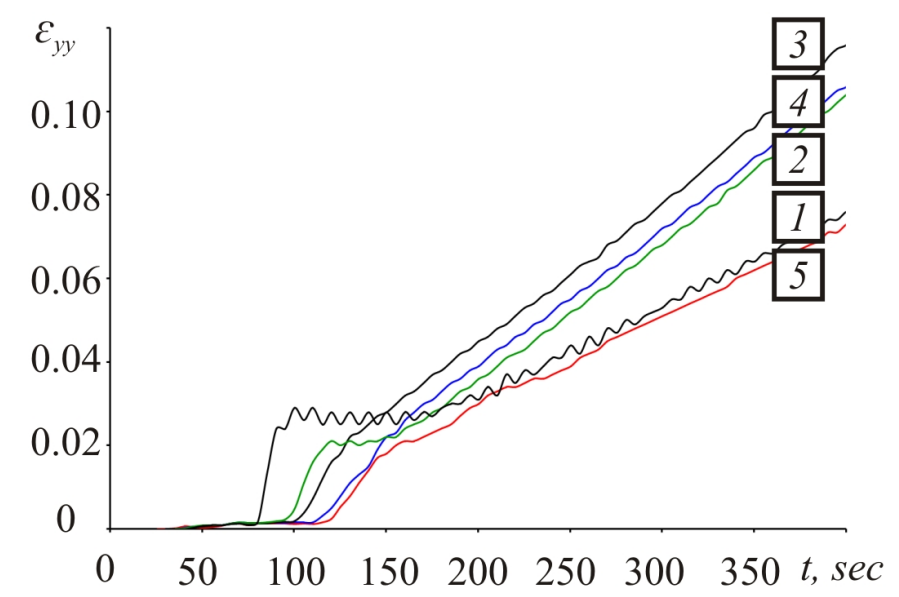

Figure 7: Time dependences of axial strain at the stage of yield plateau forming and at the material hardening stage.

In turn, the elastic unloading of peripheral specimen parts was registered at the postcritical deformation stage $(1,5)$. The elastic unloading for the first area was about $0.120 \%$, for area 5 it was $0.135 \%$.

With the aim of quantitative estimation of axial strain concentration, which is caused by localization of plastic yielding in material, the following coefficient was considered:

$$
k=\varepsilon_{y y}^{\max } / \varepsilon_{y y}
$$


where $\varepsilon_{y y}$ is the average value of axial strain, determined by using the complementary module of video system's software 'virtual extensometer'; $\varepsilon_{y y}^{\max }$ is the maximum value of axial strain on sample surface. The 'virtual extensometer' differs from mechanical extensometers generally in that the former is used after the testing procedure, during post processing, while the latter is used in real-time mode. With the help of the 'virtual extensometer' it is possible to simulate the use of several 'extensometers' on the same specimen [8]. Tab. 2 given below shows results of estimation of axial strain concentration for different material deformation stages (points I-VIII at the tensile test diagram for carbon steel).

High value of axial strain concentration coefficient is observed at the material softening stage, and also at the moment of transition through an upper yield point, which was demonstrated in this paper.

\begin{tabular}{ccccc}
\hline Point & Load, $k N$ & $\varepsilon_{y y}, \%$ & $\varepsilon_{y y}^{\max }, \%$ & $k$ \\
$I$ & 13.134 & 0.086 & - & 1.0 \\
$I I$ & 24.057 & 0.148 & - & 1.0 \\
$I I I$ & 22.504 & 0.360 & 2.580 & 7.2 \\
$I V$ & 22.326 & 1.013 & 2.962 & 2.9 \\
$V$ & 22.389 & 1.484 & 2.626 & 1.8 \\
VI & 28.742 & 4.503 & 5.935 & 1.3 \\
VII & 33.974 & 14.156 & 23.105 & 1.6 \\
VIII & 23.980 & 32.719 & 201.978 & 6.2 \\
\hline
\end{tabular}

Table 2: Estimation of axial strain concentration, which is caused by localization of plastic yielding in material.

\section{CONCLUSION}

7 he findings confirm the existence of space-time inhomogeneity in material inelastic deformation process; specifically the 'relay-race mechanism' of axial strain contribution was discovered and quantitatively investigated at the stage of yield plateau forming on the surface of a cylindrical carbon steel sample. The degree of strain macro localization was analyzed under the conditions of initiation and evolution of necking effect during uniaxial tension. Though there is significant reduction of cross-section area in the sample center, inhomogeneity of deformation process at the post critical stage is commensurable with inhomogeneity initiated by motion of axial strain wave front. Therefore, on the basis of these findings we can make a conclusion about the efficiency of digital image correlation technique and the noncontact 3-D video system. Issues of exposure of automodel parameters of inelastic deformation processes (loadingrate effect, loading conditions, shape effect) are not fully determined and require further complex investigation.

\section{REFERENCES}

[1] L.B. Zuev, V.I. Danilov, S.A. Barannikova, Plastic flow macrolocalization physics, (2008) 328.

[2] L.B. Zuev, V.I. Danilov, S.A. Barannikova, V.V. Gorbatenko, Physics of Wave Phenomena, 17(1) (2009) 66.

[3] V.E. Vildeman, J. Appl. Maths Mechs, 62(2) (1998) 281.

[4] V.E. Vildeman, A.V. Ipatova, M.P. Tretyakov, T.V. Tretyakova, Bulletin of Lobachevsky Nizhny Novgorod University, 4(5) (2011) 2063.

[5] M.A. Sutton, J.-J.Orteu, H.Schreier, Image Correlation for Shape, Motion and Deformation Measurements, (2009) 364.

[6] V.E. Vildeman, T.V. Sannikova, M.P. Tretyakov, Problems of mechanical engineering and machine reliability, 5 (2010) 106.

[7] V.E. Vildeman, T.V. Tretyakova, D.S. Lobanov, Perm State Technical University. Mechanics Bulletin, 4 (2011) 15.

[8] T.V. Tretyakova, M.P. Tretyakov, V.E. Wildemann, Perm State Technical University. Mechanics Bulletin, 2 (2011) 92.

[9] V.E. Vildeman, T.V. Tretyakova, D.S. Lobanov, Perm State Technical University. Mechanics Bulletin, 2 (2012) 34.

[10] T.V. Tretyakova, V.E. Vildeman, Factory Laboratory. Diagnostic materials, 6 (2012) 54. 